\title{
Constituição de um Grupo de Estudo na própria Escola: caminho para a (re)construção dos conhecimentos profissionais
}

DOI 10.23864/cpp-v1-n1-27

\author{
Angélica da Fontoura Garcia Silva \\ Mirtes Souza Miranda \\ Ruy Cesar Pietropaolo
}

Este artigo tem o propósito de analisar os conhecimentos necessários ao ensino das estruturas aditivas (re)significados por um grupo de professores, durante os estudos da teoria e pesquisas que tratam dessa temática. Tais conhecimentos foram evidenciados nas sessões de estudos que envolveram professores que lecionam Matemática para os anos iniciais. Trata-se de uma pesquisa de natureza qualitativa, desenvolvida no âmbito do Programa Observatório da Educação pela UNIAN, realizada numa escola pública do Estado de São Paulo, com 15 profissionais que atuam na educação básica. É importante ressaltar que a pesquisadora estava inserida no grupo e participou de todos os encontros, contribuindo para a realização dos estudos e fomentando discussões sobre teoria e prática. Os dados foram analisados à luz de investigações que discutem questões relacionadas ao conhecimento profissional docente, apoiandose nas ideias de Shulman e Ball, Thames e Phelps bem como em pesquisas que tratam das questões didáticas sobre o Campo Aditivo, com base na Teoria dos Campos Conceituais de Gerard Vergnaud. A pesquisa mostrou que a (re)significação de conhecimentos neste grupo de estudos esteve ligada, sobretudo, à retomada de conhecimentos especializados para o ensino da matemática. Os estudos teóricos realizados pelo grupo e as análises de resultados de pesquisas na área permitiram as reflexões sobre a prática e a (re)significação do conhecimento profissional dos docentes participantes. Observou-se também haver uma relação forte entre a (re)resignificação dos conhecimentos e a segurança demonstrada pelas professoras, no que se refere tanto à autoconfiança quanto à confiança mútua.

Palavras chave: Educação Matemática. Grupos de Estudo. Conhecimento Profissional Docente. Campo Conceitual Aditivo. 


\title{
Formation of a Study Group in the School itself: a way to (re) build professional knowledge
}

\author{
Angélica da Fontoura Garcia Silva \\ Mirtes Souza Miranda \\ Ruy Cesar Pietropaolo
}

\begin{abstract}
This paper aims to analyze the knowledge skills which are necessary for the teaching of additive structures that have been (re)significances by a group of teachers, during studies of theory and research that deal with this subject. Such knowledge was evidenciated in studies involving teachers who teach Math to the early years. It is about a qualitative research developed on the Education. Observatory Program, by the UNIAN, performed in a public school in the State of São Paulo, with 15 professionals who work in basic education. It is important noticing that theresearcherhasparticipated bothin theGroupandinall meetings, thus contributing to the realization of studies and encouraging discussions on the theory and practice. The data were analysed in the light of investigations that discuss issues related to professional knowledge, drawing on theideas ofShulmanand Ball, Thamesand Phelpsaswell asin researchdealing witheducationalissuesontheAdditiveFieldonthebasis of Gerard Vergnaud's Conceptual Fields Theory. Research has shown that the knowledge (re)signification in this study group was related, above all, to the resumption of expertise knowledge for the teaching of mathematics. The theoretical studies carried out by the group and the outcome analysis of researches in the area have allowed reflections on practice and the (re)signification of the professional knowledge of participating teachers. It was observed a strong relation between the (re)signification of knowledge and the security, demonstrated by the teachers, in regards to self-confidence as well as to mutual trust.
\end{abstract}

Keywords: Mathematics Education. Study Groups. Teacher Professional Knowledge. Conceptual Additive Field. 


\section{Introdução}

Este artigo discute parte dos resultados da pesquisa7 realizada no interior de uma escola pública de São Paulo, a partir da constituição de um grupo para estudar o Campo Conceitual Aditivo à luz das ideias defendidas por Vergnaud (1990).

Nesse trabalho, procuramos investigar os indícios de (re)significação dos conhecimentos necessários ao ensino de noções concernentes as estruturas aditivas explicitadas pelas participantes, durante o estudo da teoria, a análise de resultados de pesquisas, bem como durante a discussão sobre situações elaboradas por eles, antes dos estudos e sobre protocolos produzidos por alunos. Para esta comunicação apresentaremos resultados encontrados nas $1^{\mathrm{a}}, 7^{\mathrm{a}}$ e $14^{\mathrm{a}}$ sessões de estudo.

\section{Relevância e Fundamentação teórica}

A (re)significação de conhecimentos para o ensino de um conteúdo, num grupo de estudos depende, muitas vezes, da retomada dos conhecimentos específicos desse conteúdo, que podem favorecer a ampliação de outros conhecimentos relacionados a esse mesmo conteúdo, como o didático e curricular, por exemplo. Acreditamos que isso favorece o surgimento de maior segurança para estes profissionais tanto para aplicação como na análise das situações propostas.

Consideramos, assim como Vergnaud (1990, 2004, 2009), que o grande desafio do professor é confrontar seus alunos com diferentes situações que lhes permitam ampliar suas capacidades e, assim, favorecer a evolução de esquemas de resolução. Vergnaud (2004), considera como consequências do trabalho doprofessor:

[...] que seu primeiro ato de mediação é a escolha de situações, [...] $\mathrm{O}$ professor toma decisões o tempo todo, mas a escolha de situações é, provavelmente, a decisão mais importante na lógica dos campos conceituais, porque ela supõe tanto uma reflexão epistemológica e uma adaptação aos alunos e as questões que venham a surgir [...] (VERGNAUD, 2004, p. 37-38)

Consideramos, assim como o autor, que as competências necessárias para a resolução de problemas se desenvolvem por meio de diferentes experiências que a criança tem ao longo da vida. Portanto, a escola deve favorecer uma gama de situações diversificadas de aprendizagem, para que organize informações, levante hipóteses e elabore suas conclusões. Para Vergnaud (2009):

7 Neste artigo apresentamos resultados parciais da pesquisa de Miranda (2014)

ISSN 2526-2882 
[...] Os conhecimentos que a criança adquire devem ser construídos por ela em relação direta com as operações que ela, criança, é capaz de fazer sobre a realidade, com os conceitos que ela progressivamente constrói. [...]. (VERGNAUD, 2009, p. 15)

Da mesma forma, o autor considera que o Campo Aditivo não é um conhecimento trivial, uma vez que:

O campo conceitual das estruturas aditivas fornece numerosos exemplos de situações, nas quais a escolha de uma operação e a dos dados sobre os quais ela se aplica é delicada, exigindo um arranjo específico, uma ajuda significativa do adulto, eventualmente, uma representação simbólica original (VERGNAUD, 2011, p. 17).

Uma das ideias fundamentais de Vergnaud (1990) é a de Conceito. Para o autor Conceito é constituído pela tríade: "[...] (S, I, R), S: conjunto de situações de referência, I: Conjunto de invariantes e R: Conjunto de representações simbólicas" (VERGNAUD, 1990, p.139). Vergnaud (2009) afirma também que as relações estabelecidas nesse campo conceitual são relações ternárias ${ }^{8}$. Nesse sentido o autor considera a multiplicidade de estruturas aditivas que podem ocorrer em função das relações estabelecidas entre as diversas situações-problema. Assim, o autor esclarece que um bom caminho é iniciar os estudos pela análise das seis categorias aditivas com seus respectivos esquemas. O autor considera as seguintes categorias:

- Primeira categoria - duas medidas se compõem para resultar uma terceira. Segunda categoria - uma transformação opera sobre uma medida para resultar em outra medida. Terceira categoria - uma relação liga duas medidas. Quarta categoria - duas transformações se compõem para resultar em uma transformação. Quinta categoria - uma transformação opera sobre um estado relativo (uma relação) para resultar em um estado relativo. Sexta categoria - dois estados relativos (relações) se compõem para resultar em um estado relativo (VERGNAUD, 2009, p. 200).

Em nosso grupo de estudos foram realizadas as análises das três primeiras categorias aditivas e seus esquemas sagitais, conforme apresentadas pelo autor, Figura 1.

Figura 1: Esquema sagital apresentado por Vergnaud (2009)

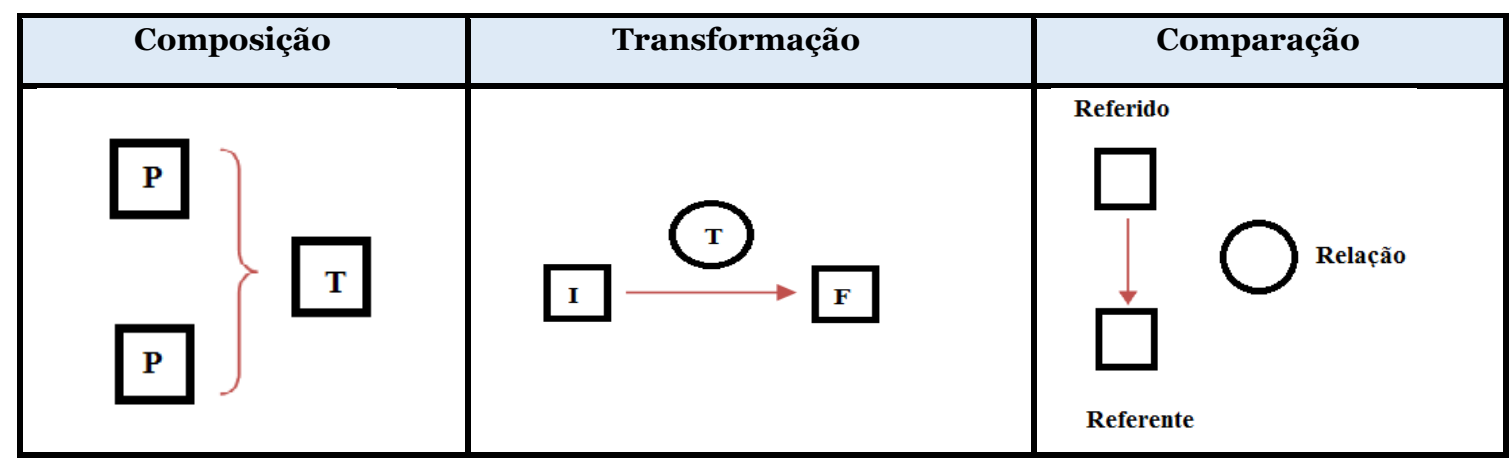

Fonte: Vergnaud (2009, p. 202, 203)

\footnotetext{
${ }^{8}$ Segundo Vergnaud (2009) as relações ternárias são aquelas "que ligam três elementos entre si Pedro está entre André e Joana”.
} 
Nossa compreensão é de que os professores devem ter conhecimentos sobre o Campo Conceitual Aditivo e sobre a classificação de situações, proposta por Vergnaud (1990, 2004, 2009), pois a aquisição desse conhecimento pode favorecer o enriquecimento das ações pedagógicas, para o ensino desse conteúdo.

Para proceder a análise de dados nos utilizamos de teorias que analisam o Conhecimento Profissional Docente. As ideias de Shulman (1986) preconizou os estudos acerca de quais são os conhecimentos necessários para a ação docente, em relação aos conteúdos que serão ensinados. Shulman (1986) incentiva a reflexão sobre o que os professores precisam saber para ensinar seus alunos e como esses conhecimentos são construídos. Segundo ele, o conhecimento profissional docente pode ser classificado em três categorias:

Conhecimento do conteúdo; Conhecimento Pedagógico do Conteúdo e Conhecimento Curricular. Ball, Thames e Phelps (2008), tomando como ponto de partida os estudos de Shulman, discutem os conhecimentos necessários para a atuação do professor que leciona Matemática. As investigações realizadas por Ball e colegas indicaram que existe uma relação intrínseca entre o conhecimento matemático dos professores e o desempenho dos alunos. Esses pesquisadores apresentam o esquema seguinte, ampliando as ideias de Shulman:

Figura 2: Esquema de categorias de conhecimento segundo Shulman (1986) em comparação ao esquema de Ball et al (2008) ${ }^{9}$

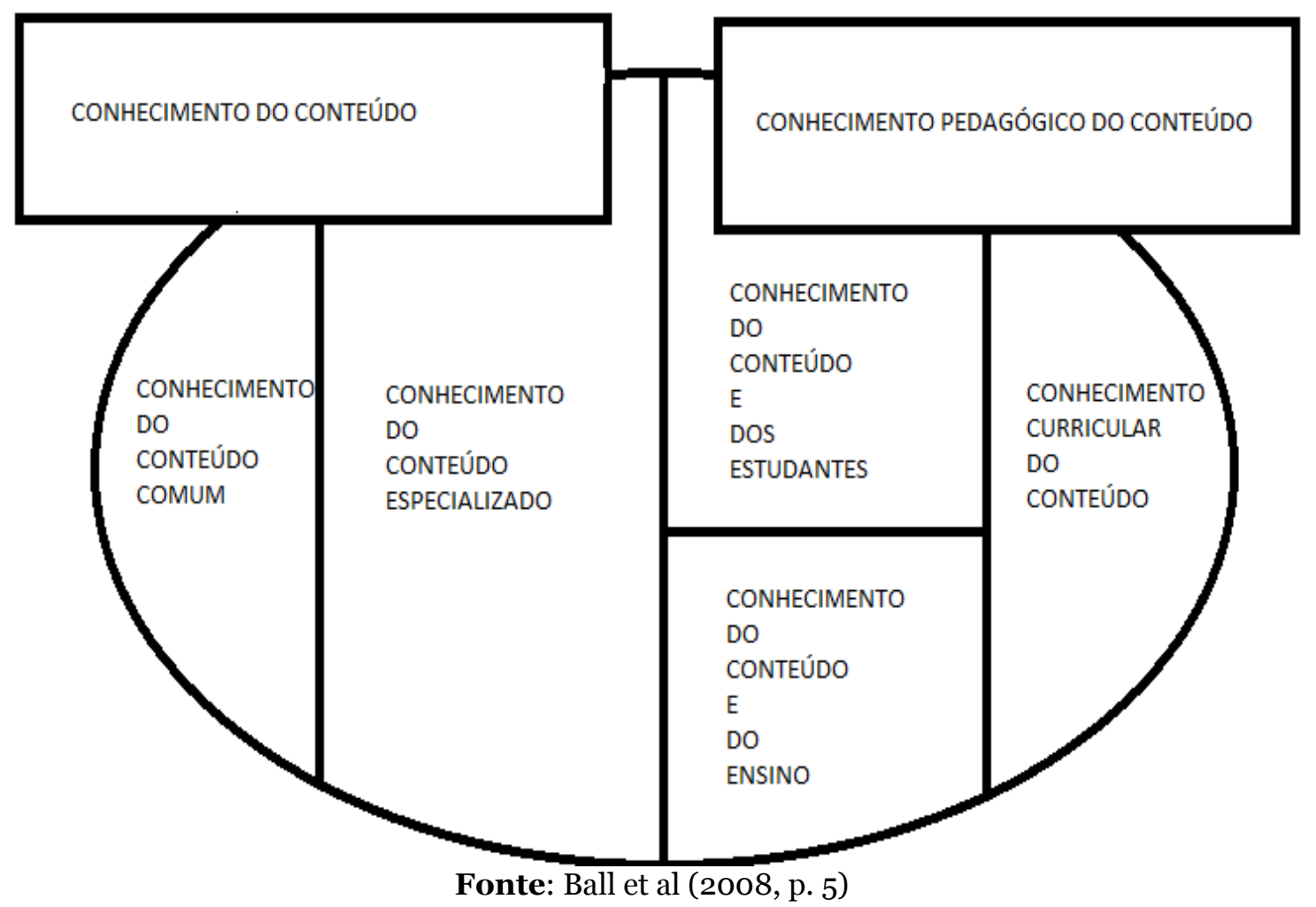

9 Tradução nossa para o esquema de Ball et al (2008)

ISSN 2526-2882

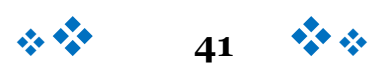


Considerando nossa temática de investigação, campo conceitual aditivo, e as categorias de Ball, nos inspiramos em Pereira (2013) para apresentar uma interpretação dos tipos de conhecimentos propostos por Ball et al (2008) sobre Campo Conceitual Aditivo.

\section{Conhecimento Comum do Conteúdo (Common Content Knowledge - CCK)}

Um exemplo típico de conhecimento básico necessário a qualquer pessoa que passou pelos bancos de escola e estudou Matemática, professor ou não, é a compreensão das ideias que envolvem a adição e a subtração, bem como a utilização de um algoritmo para realizar seu cálculo, além da capacidade para identificar um erro no resultado de uma aplicação para uso próprio.

\section{Conhecimento Especializado do Conteúdo (Specialized Content Knowledge - SCK)}

Qual o conhecimento que permite ao professor lidar com situações imprevistas, ou ao desenvolver a temática em sala ou ao interpretar resoluções dos alunos, principalmente quando são diferentes dos algoritmos usuais? Com base em Ball et al (2008), avaliamos que para ensinar os algoritmos das operações, seria importante, por exemplo, que o professor fosse capaz, por exemplo, de justificar matematicamente a não existência do "vai um". Já na subtração, dentre outros conhecimentos, seria interessante que o docente compreendesse também as propriedades matemáticas envolvidas em uma subtração, que permitem, por exemplo, adicionar (ou subtrair) outro valor qualquer aos dois termos (minuendo e subtraendo), sem alterar o resultado. Além disso, é importante saber ainda que a adição ou a subtração desses valores podem ser efetuadas em ordens diferentes, de forma que, se adicione uma dezena (ou seus múltiplos) para que o valor das unidades adicionadas ao minuendo passe a ser superior ao valor indicado na unidade do subtraendo.

\section{Conhecimento do Conteúdo e dos Estudantes (Knowledge of Content and Students - KCS)}

Um conhecimento necessário para compreender quais são os erros comuns dos estudantes e que permita aos professores a proposição de estratégias de ensino adequadas à superação desses erros, é o que capacita esse professor a identificar e analisar situações que levam os alunos a valer-se de indícios linguísticos presentes no texto para realizar os cálculos que produzem a solução. Por exemplo, na situação-problema a seguir, o professor pode se valer desse tipo de conhecimento ao analisar a resolução apresentada pelos seus alunos.

Assim, na situação Carlos tem 6 carrinhos e Cida tem 9 carrinhos. Quantos carrinhos Cida têm a mais do que Carlos? é importante que o professor perceba que, se as crianças, diante desse problema, tendem a adicionar 6 a 9, possivelmente foram induzidas pela palavra 
"mais" presente no enunciado. Se isso for confirmado, seria importante que o profissional soubesse que esse é um forte indício de que seus alunos não compreenderam a estrutura do problema, ou ainda, que, em algum momento do ensino, tenham sido levadas a escolher a operação que resolve o problema por meio da identificação de palavras-chave (mais, menos, juntar, perder, ganhar, dentre outras).

Dessa forma, consideramos importante que o professor investigue a origem das respostas dos estudantes e quais as possíveis causas que os levaram aos equívocos.

\section{Conhecimento do Conteúdo e Ensino (Knowledge of Content and Teaching - KCT)}

Esse conhecimento refere-se à relação entre as questões pedagógicas que podem interferir no processo de ensino e aprendizagem de um tema e a compreensão de conteúdos específicos da Matemática. Como exemplo, podemos citar o foco dos estudos do grupo que investigamos: a compreensão da necessidade de trabalhar com os diferentes tipos de situações apresentadas por Gerard Vergnaud para o Campo Conceitual Aditivo para permitir a construção desse conceito.

\section{Conhecimento do Conteúdo e Currículo (Knowledge of Content and Curriculum $-\mathrm{KCC})$}

Um exemplo do conhecimento que o professor deve ter do currículo é o que se refere às situações do Campo Aditivo adequadas a cada segmento de ensino em que o professor leciona.

Assim, concordamos com Ball et al (2008) quando afirma que os professores precisam construir conhecimentos específicos para o ensino de Matemática, pois só assim poderão intervir no processo de aquisição de conhecimentos dos alunos, planejar e replanejar suas ações, analisando os conceitos que estão implícitos e observando quais são os avanços e dificuldades encontradas pelos estudantes na realização das atividades. Além disso, esse conhecimento favorece a compreensão do Currículo, considerando em quais concepções está embasado.

Dessa forma, neste estudo buscamos analisar o processo de (re)significação desses conhecimentos em um grupo de professores participantes de um grupo de estudos. Em nossa revisão de literatura encontramos forte discussão apresentada nas pesquisas brasileiras sobre a importância da constituição de grupos de estudos no interior das escolas.

Pesquisas como as de Moraes e Gomes (2004) e Etcheverria (2008) destacam tal importância, considerando que favorece discussões que ampliam os conhecimentos sobre o currículo. Esses autores, também recomendam que se levem em conta as necessidades 
expressadas pelos próprios professores e enfatizam a importância de que a solicitação da constituição de grupos de estudos “(...) parta do coletivo da escola. Nessa situação existirá na escola um clima positivo para uma reflexão conjunta sobre o currículo e sua reconstrução" (MORAES e GOMES, 2004, p.210). Quanto à formação de grupos de estudo na própria escola nos apoiamos em Nóvoa (1997). O autor considera que:

A troca de experiências e a partilha de saberes consolidam espaços de formação mútua, nos quais cada professor é chamado a desempenhar, simultaneamente, o papel de formador e de formando. O diálogo entre os professores é fundamental para consolidar saberes emergentes da prática profissional. (NÒVOA, 1997, p.26)

Etcheverria (2008) também investigou um grupo formado na própria escola e observou que as relações foram fortalecidas e oportunizaram a ampliação dos conhecimentos dos envolvidos. Segundo a autora, as sessões de estudo possibilitaram que: “(...) as professoras revelassem seus medos e emoções, superassem inseguranças e dificuldades, sendo que o espaço de discussão e trocas foi mediado com base no respeito e aceitação das diferenças. (ETCHEVERRIA, 2008, p.81). Nesse sentido, procuramos, assim como apresentado pela autora, fortalecer os laços e incentivar o trabalho colaborativo no grupo investigado em nosso estudo.

\section{Procedimentos Metodológicos}

Trata-se de uma pesquisa de natureza qualitativa. A coleta de dados se deu por meio da proposição de um questionário inicial, gravações em vídeos e excertos de materiais produzidos pelos professores ${ }^{10}$. A aplicação do questionário - de caráter diagnóstico - visava identificar o significado dado pelos professores ao ensino das estruturas antes das sessões de estudo. Neste artigo, apresentamos os resultados da análise deste questionário e analisamos os depoimentos coletados em uma das sessões de formação. Nela, as professoras foram convidadas a analisar as situações por elas elaboradas antes de iniciar os estudos.

Reiteramos que a constituição do grupo se deu a partir da adesão de 15 professores mais a pesquisadora. Esse grupo era composto, inicialmente, por uma professora de Educação Física, uma professora de Arte, uma professora Coordenadora Pedagógica, uma designada para a função de Diretora, outra de Vice-diretora, uma que exercia a função de Professora Mediadora e nove professoras polivalentes que, entre as demais disciplinas, lecionam também Matemática para os anos iniciais do Ensino Fundamental.

${ }^{10}$ VERGNAUD, G. (Universidade Bandeirante de São Paulo- UNIBAN (hoje UNIAN) - Campus Marte) Aula, 2010. 
Para a realização desta investigação analisamos os dados coletados em 04 das 14 sessões de estudo com o grupo com uma hora semanal. Para melhor compreensão do leitor, apresentamos no quadro a seguir, de forma sistematizada, como organizamos e desenvolvemos as ações no grupo de estudo, em negrito marcarmos as sessões aqui analisadas (encontros: 1,8, e 14).

\begin{tabular}{|c|c|c|}
\hline Encontros & Data & Atividade Desenvolvida \\
\hline $\begin{array}{c}1^{\circ} \\
\text { encontro }\end{array}$ & $04 / 04 / 2013$ & $\begin{array}{ll}\checkmark & \text { Formação do Grupo de estudos. } \\
\checkmark & \text { Reflexões dos professores a respeito da sua própria prática. } \\
\checkmark & \text { Elahoracão de seis situacões de adicão ousuhtracão }\end{array}$ \\
\hline $\begin{array}{c}2^{\mathrm{O}} \\
\text { encontro }\end{array}$ & $11 / 04 / 2013$ & $\checkmark \quad$ Retomada das atividades do encontro anterior. \\
\hline $\begin{array}{l}3^{\mathrm{o}} \\
\text { encontro }\end{array}$ & $18 / 04 / 2013$ & $\begin{array}{l}\checkmark \text { Estudos sobre a teoria do Campo Conceitual Aditivo, segundo Vergnaud, por meio da } \\
\text { leitura do material de apoio teórico Repensando a Adição e Subtração - Contribuições da } \\
\text { Teoria dos Campos Conceituais. }\end{array}$ \\
\hline $\begin{array}{c}4^{\mathrm{o}} \\
\text { encontro }\end{array}$ & $26 / 04 / 2013$ & $\begin{array}{ll}\checkmark & \text { Estudos e análises de situações de Composição, segundo a teoria de Vergnaud. } \\
\checkmark & \text { Atividade prática: elaboração (oral) de situação deComposição. }\end{array}$ \\
\hline $\begin{array}{c}5^{\mathrm{O}} \\
\text { encontro }\end{array}$ & 29/04/2013 & $\begin{array}{l}\checkmark \quad \text { Estudos e análises de situações de Transformaçãa e Comparação, segundo a teoria de } \\
\text { Vergnaud. } \\
\checkmark \quad \text { Atividade prática: elaboração (oral) de situação deTransformação. }\end{array}$ \\
\hline $\begin{array}{c}6^{0} \\
\text { encontro }\end{array}$ & 03/05/2013 & $\begin{array}{l}\checkmark \quad \text { Retomada dos estudos sobre situação de Composição e Transformação e Comparação, } \\
\text { utilizando os diagramas Vergnaud apresentados por Magina et al (2008). }\end{array}$ \\
\hline $\begin{array}{c}7^{0} \\
\text { encontro }\end{array}$ & 06/05/2013 & $\checkmark$ Classificação das situações elaboradas por elas nos encontros anteriores. \\
\hline $\begin{array}{c}\mathbf{8}^{\mathbf{o}} \\
\text { encontro }\end{array}$ & $10 / 05 / 2013$ & $\begin{array}{l}\checkmark \quad \text { Retomada das ideias discutidas sobre a teoria do Campo Conceitual Aditivo } \\
\text { e as classificações de situações propostas por Vergnaud } \\
\checkmark \quad \text { Análise e classificação dos problemas elaborados pelos professores no } \\
\text { primeiro dia de estudo. }\end{array}$ \\
\hline $\begin{array}{c}9^{\circ} \\
\text { encontro }\end{array}$ & $13 / 05 / 2013$ & $\begin{array}{l}\checkmark \quad \text { Estudos sobre esquemas, segundo a teoria do Campo Conceitual Aditivo, com aporte } \\
\text { teórico da tese de doutorado de: Santana (2010). }\end{array}$ \\
\hline $\begin{array}{c}10^{\circ} \\
\text { encontro }\end{array}$ & $17 / 05 / 2013$ & $\begin{array}{l}\checkmark \quad \text { Discussões e reflexões sobre processo formativo, teoria do Campo Conceitual Aditivo, } \\
\quad \text { Currículo e provas de concurso para professores. } \\
\checkmark \quad \text { Análise da questão da prova do Mérito de } 2012\end{array}$ \\
\hline $\begin{array}{c}11^{\circ} \\
\text { encontro }\end{array}$ & 03/06/2013 & $\begin{array}{l}\checkmark \text { Estudos sobre os Esquemas de resolução de problemas e reflexão sobre os esquemas } \\
\text { usados pelas crianças (alunos dos professores participantes) e os resultados encontrados } \\
\text { na pesquisa de Santana (2010) - Atividade de leitura e reflexões (oral) }\end{array}$ \\
\hline $\begin{array}{c}12^{\mathrm{o}} \\
\text { encontro }\end{array}$ & $17 / 06 / 2013$ & $\begin{array}{l}\checkmark \text { Apresentação para o grupo da sugestão de análise das classificações de situações do } \\
\text { Campo Conceitual Aditivo, segundo as concepções deVergnaud. }\end{array}$ \\
\hline $\begin{array}{c}13^{\circ} \\
\text { encontro }\end{array}$ & 19/06/2013 & $\begin{array}{l}\checkmark \quad \text { Análise dos protocolos dos alunos- os esquemas usados por eles, os tipos de erros e } \\
\text { acertos nas diferentes categorias descritas porVergnaud. } \\
\checkmark \quad \begin{array}{l}\text { Discussão e reflexão sobre a importância de diversificar as situações propostas para os } \\
\text { alunos. }\end{array} \\
\checkmark \quad \begin{array}{l}\text { Reflexão acerca da crença apresentada pelos professores, no início dos estudos de grupo, } \\
\text { sobre } 0 \text { fato de ameadicãó mais fácil ame a subtracão. }\end{array}\end{array}$ \\
\hline $\begin{array}{c}14^{\circ} \\
\text { Encontro }\end{array}$ & 21/o6/2013 & $\begin{array}{l}\text { Encerramento das atividades do primeiro semestre, confraternização e } \\
\text { reflexões a respeito de quais foram as contribuições dos estudos realizados } \\
\text { em relação ao desenvolvimento do professor. }\end{array}$ \\
\hline
\end{tabular}

Quadro 6: Descrição das atividades desenvolvidas em cada sessão de estudo

\section{Análise e Discussão dos Dados}

A atividade inicial do grupo coletada por meio do questionário foi a solicitação da elaboração de uma lista com seis situações- problema cuja solução envolvesse adição ou 
subtração. Tal proposta objetivou investigar os conhecimentos do conteúdo e do ensino das professoras sobre os significados do Campo Conceitual Aditivo, na perspectiva de Ball et al (2008).

Como resultado dessa fase inicial, foram elaboradas pelo grupo, 51 situaçõesproblema, que, posteriormente, foram discutidas e analisadas à luz da classificação apresentada por Vergnaud (1990, 2004, 2009), no que se refere às relações terciárias. Dentre elas, 34 representavam relações ternárias. Dessas situações, 03 foram consideradas inconsistentes. Nesse sentido, apresentaremos sinteticamente nossa análise das 31 situações, dentre as quais, 14 eram de composição, sendo 9 prototípicas (todo desconhecido); 14 de transformação também prototípicas (o estado inicial desconhecido) e 3 de comparação, destas nenhuma buscava questionar o valor do referente. Observamos ainda que, no geral, houve por parte de todas as participantes a preocupação em apresentar as crianças situações próximas ao cotidiano ao qual vivenciam demonstrando estarem em consonância com as orientações curriculares oficiais.

Quanto as categorias analisadas, cada uma delas está explicitada nos parágrafos que seguem, nos quais são apresentados exemplos das situações-problema elaboradas pelo grupo. A situação representada no diagrama a seguir exemplifica uma das nove situaçõesproblema de Composição do tipo prototípicas, criadas pelas professoras.

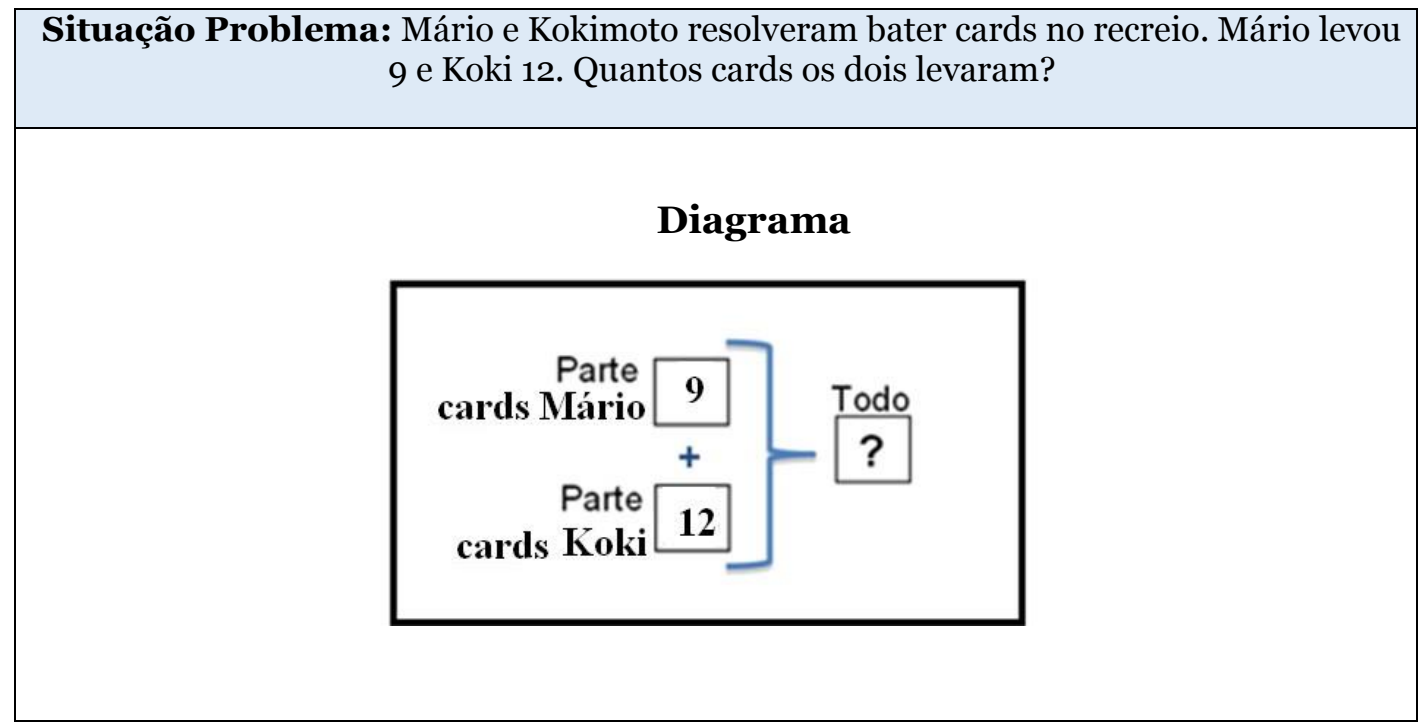

Quadro 1: Situação de Composição criada por uma professora do grupo e o diagrama conforme proposto por Vergnaud (2009)

A situação-problema apresentada é de composição, cujas partes (quantidade de cards de Mário e Koki) são conhecidas e se questiona o valor do todo (total de cards levados pelas duas crianças). Esse tipo de situação é respondida de forma correta por quase todas as crianças 
no final do primeiro ano do ensino fundamental. Segundo Vergnaud (2010) ${ }^{11}$, situações desse tipo são resolvidas corretamente por crianças por volta dos 5 e 6 anos.

Além das situações prototípicas, foram elaboradas pelas professoras cinco situaçõesproblema envolvendo inversão, ou seja, as que apresentam o todo e uma das partes e perguntase sobre o valor da parte restante. Para exemplificar, apresentamos a situação problema a seguir:

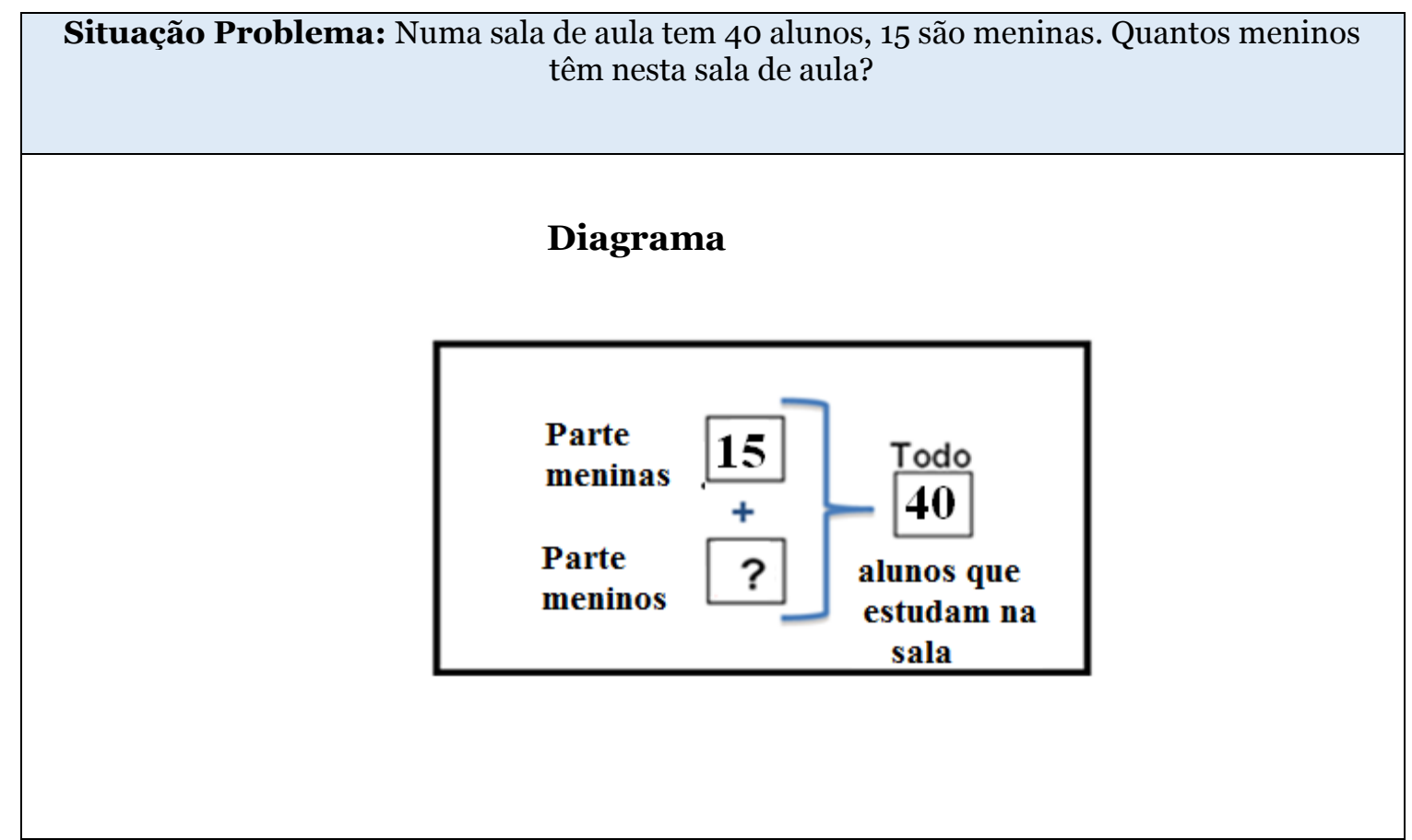

Quadro 2: Situação Composição criada por uma professora do grupo e o diagrama conforme proposto por Vergnaud (2009)

Trata-se de uma situação de composição em que o todo (o número de alunos que estudam na sala) é conhecido e uma das partes (o número de meninas) também, e se questiona a outra parte, que é desconhecida (o número de meninos).

Outro tipo de situação elaborada pelas professoras, participantes desta pesquisa, foi o que Vergnaud (1990, 2004, 2009) identificou como Transformação prototípica. Quatorze situações foram elaboradas nessa categoria. A análise foi realizada com base no diagrama a seguir:

${ }_{11}^{3}$ Notas da autora durante a participação do curso monográfico "Teoria dos Campos Conceituais" da Escola de Altos Estudos da CAPES junto ao Programa de Pós-Graduação stricto sensu em Educação Matemática da UNIBAN (hoje UNIAN) ministrado por Gerard Vergnaud, no período de 5 a 13 de agosto de 2010. 


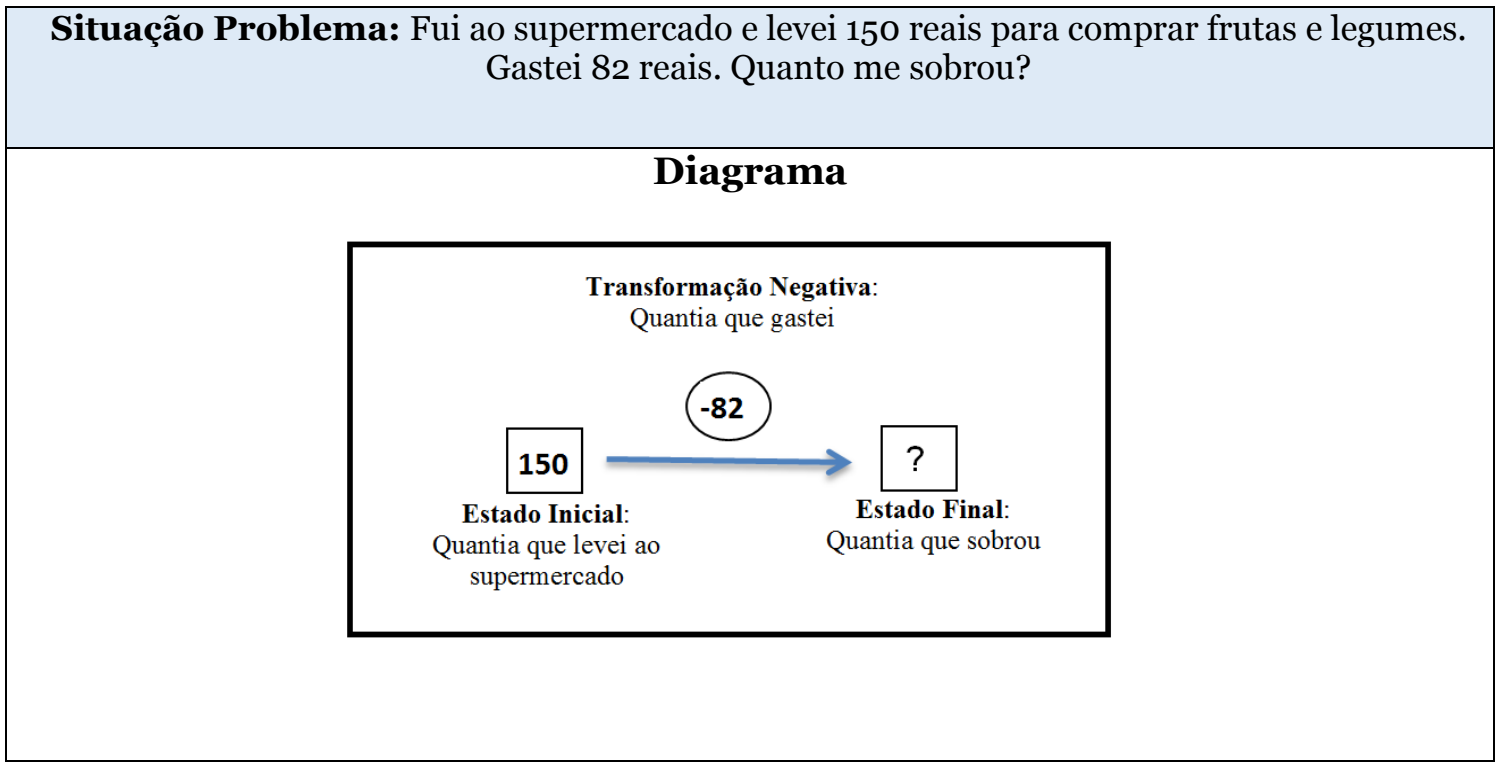

Quadro 3: Situação Transformação criada por uma professora do grupo e o diagrama conforme proposto por Vergnaud (2009)

Em relação às situações-problema que envolvem a ideia de comparação entre os termos, em que é dado o Referente e se quer saber o valor do Referido, encontramos somente uma situação, conforme indicamos a seguir:

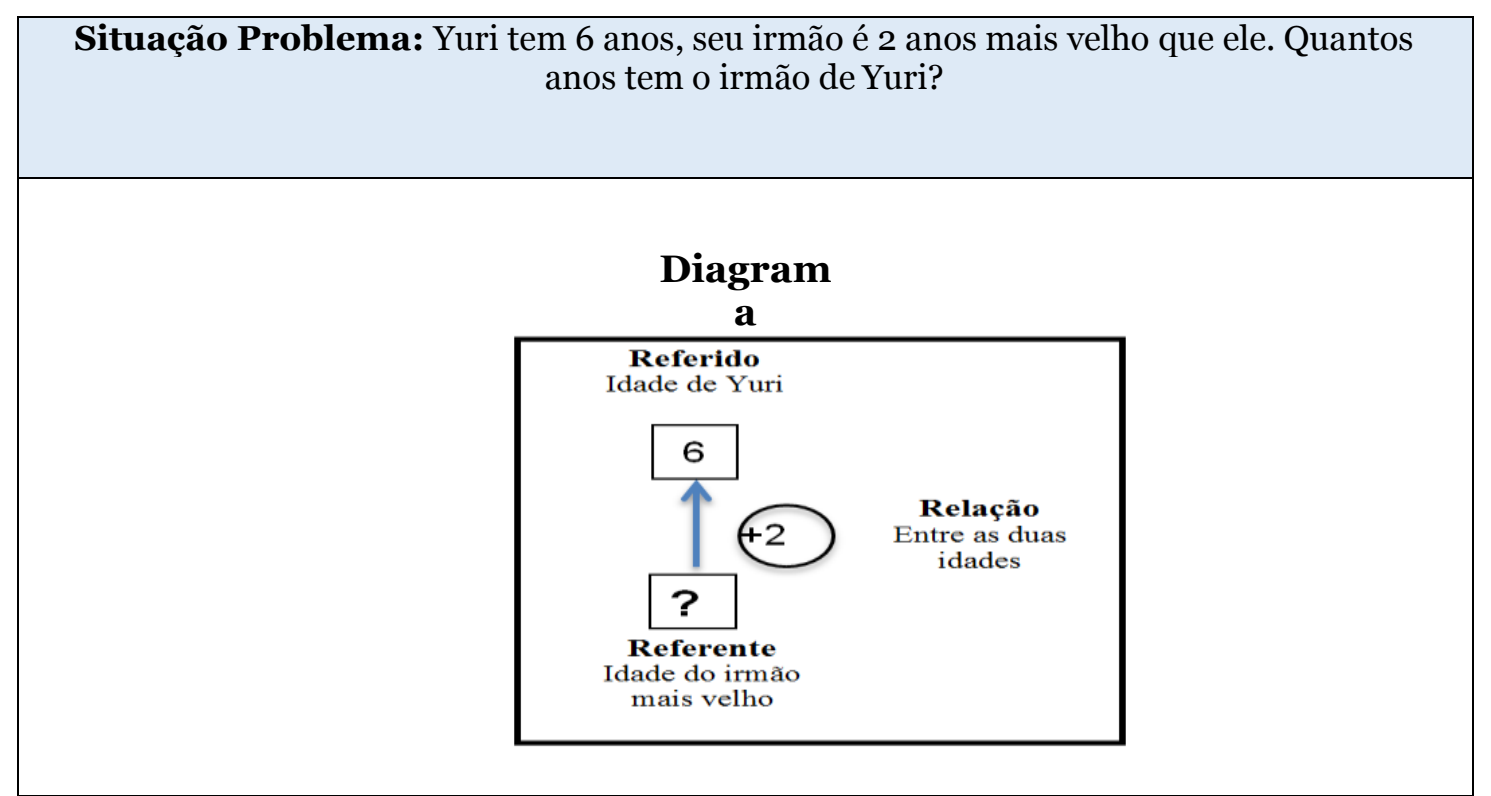

Quadro 4: Situação Comparação em que se questinona o referente, elaborada por uma das professoras e o diagrama conforme proposto por Vergnaud (2009)

Nessa situação-problema foi dado o referido (idade de Yuri) e a relação entre elas informa o tempo que o irmão é mais velho que Yuri (2 anos); investiga-se o referente (idade do irmão mais velho). 
Outro tipo de situações-problema classificada por Vergnaud (1990) é aquele em que o referente e o referido são dados no enunciado dos problemas e se quer saber qual é a relação que existe entre eles. A análise do material elaborado pelas professoras do Grupo de Estudos revelou apenas dois problemas com tais características, ou seja, os grupos são informados no enunciado e solicita-se que o aluno descubra a relação existente entre eles.

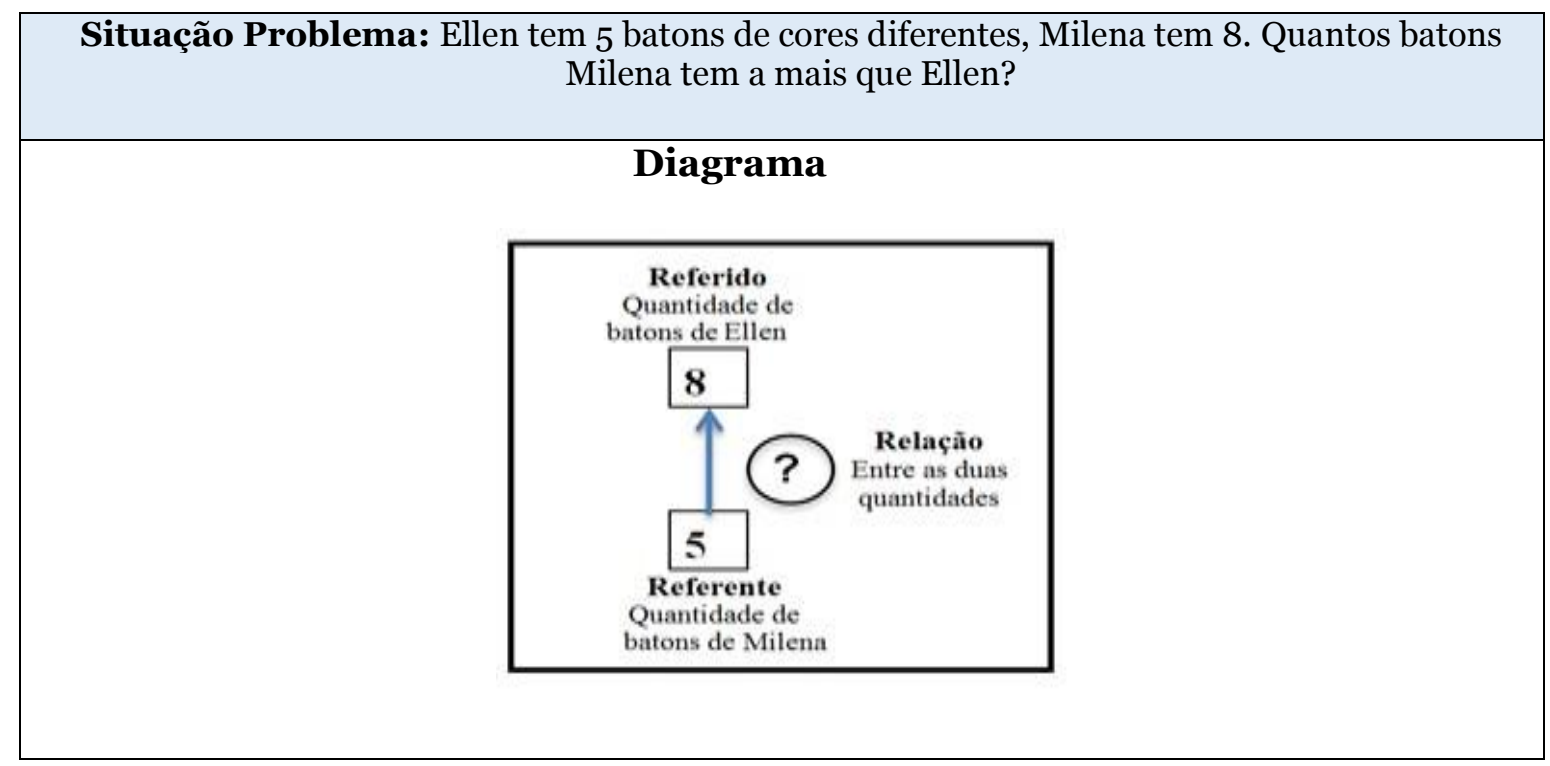

Quadro 5: Situação Comparação em que se questinona a relação, elaborada por uma das professoras e o diagrama conforme proposto por Vergnaud (2009)

Encontramos 03 problemas inconsistentes, ou seja, aqueles em que faltam dados fundamentais para que o aluno tenha condições de criar esquemas para sua resolução, como podemos perceber nos excertos a seguir:

Rogério nasceu em 1962; quantos anos ele possui? (PROFESSORA SAFIRA) A professora Helena pediu para que cada um de seus alunos trouxesse um caderno de desenho para a aula de Arte. Quantos cadernos eles trouxeram? (PROFESSORA EMANUELA)

Maria tem 236 caixas e João tem 107 caixas a mais. Quantas balas os dois tem juntos? (PROFESSORA EVA)

Estas informações nos levam a constatar que aproximadamente 74,2 \% das situaçõesproblema ternárias válidas que foram elaboradas pelas professoras eram prototípicas. Vergnaud (2010) observa que as crianças, antes de chegarem à escola, já reconhecem essas situações, sobretudo, aquelas que vivenciam experiências semelhantes nas relações que estabelecem em seu cotidiano. Segundo o autor, os alunos muitas vezes não precisam se valer de representações simbólicas para resolver situações prototípicas.

Entretanto, Vergnaud (2010) ressalta a importância de o professor apresentar situações diversificadas observando seu grau de dificuldade. Seguindo suas origens piagetianas, o autor 
afirma: "Se o conhecimento é adaptação, para as crianças aprenderem temos que desestabilizálas. Se as crianças não têm motivo para se adaptar a situação nova, por que aprender? Não há motivo para aprender coisas novas”. (VERGNAUD, 2010, notas de aula)12

Assim como o autor, consideramos fundamental que o professor ofereça diferentes situações que representem desafios a serem enfrentados pelos alunos, como oportunidades para a aplicação de esquemas que eles já construíram, assim como para a reflexão sobre novas formas de resolução e para a construção de novos conhecimentos. Infelizmente nossos dados evidenciam que isso que não estava ocorrendo.

Vergnaud (2010, notas de aula) chama a atenção para que o professor favoreça ao aluno vivências que possibilitem o desenvolvimento de esquemas novos, "que as crianças ainda não viram, não aprenderam". Considera também que, "como um conceito, o esquema tem um valor universal para todas as situações que pertençam a essa mesma classe”. Daí a importância de apresentar aos alunos uma variedade de situações.

Nesse sentido, analisando os resultados evidenciados no início dos estudos sob o ponto de vista de Shulman (1986) e de Ball et al (2008), acreditamos que a falta de domínio desse conteúdo específico, ou seja, a dificuldade de reconhecimento e compreensão das diversas situações do campo conceitual aditivo implicaria também na falta de conhecimentos do conteúdo e do ensino das ideias envolvendo a adição e subtração.

Reiteramos para a realização desta investigação analisamos além dos os dados coletados nessa primeira sessão os dados de outras o3 sessões de estudo com o grupo com uma hora semanal.

\section{As professoras participantes discutem sobre as situações-problema elaboradas por elas no início dos estudos}

$\mathrm{Na}$ oitava sessão de estudos retomamos os problemas que foram elaborados por elas nos primeiros dois encontros, a fim de analisarmos sob o ponto de vista de Shulman (1986) e Ball et al (2008). Ao propor a leitura das situações- problema, foi possível perceber que havia indícios da (re)significação de conhecimento a respeito dos conceitos sobre a Teoria do Campo Conceitual. A seguir apresentamos um diálogo retirado das discussões realizadas pelo grupo durante a sessão de estudos. A Professora Rebeka, por exemplo, percebeu que em sua elaboração inicial havia priorizado os problemas prototípicos.

12 VERGNAUD, G. (Universidade Bandeirante de São Paulo- UNIBAN (hoje UNIAN)- Campus Marte) Aula, 2010 
- O meu é só protótipo. Que horror! (PROFESSORAREBEKA)

- Se ficarmos só nos modelos prototípicos o que irá acontecer? (PESQUISADORA)

- Não tem desafio, pode ser que com o tempo fique até desestimulante. (PROFESSORA EMANUELA)

Quadro 7: Diálogo que retrata o momento de análise vivenciado por professoras participantes durante a sessão de estudos

A exclamação da Professora Rebeka e a observação da Professora Emanuela nos permitem inferir que, possivelmente, elas levaram em conta os estudos e reflexões ocorridos nos primeiros seis encontros. Neles havíamos discutido apoiados nos estudos de Vergnaud, sobre a necessidade de trabalhar com as diferentes categorias e sobre o fato de que problemas prototípicos são muitas vezes reconhecidos pelas crianças mesmo antes delas chegarem à escola.

Isso nos remete aos estudos de Serrazina, que discute sobre a relação entre o conhecimento e a autoconfiança. Segundo a autora, a partir do aprimoramento do conhecimento os professores: “(...) são capazes de reflectir nas suas práticas. Isto pressupõe um elevado grau de conscientização que os ajude a reconhecer as suas falhas e fraquezas e a assumir um forte desejo de ultrapassá-las”. (SERRAZINA, 1999, p. 163). No Brasil isso também foi observado por Etcheverria (2008) em um grupo que estudava geometria.

Vale ressaltar que destacamos até aqui somente um episódio, mas tivemos nessa mesma sessão mais evidências tanto da (re)significação de conhecimentos como sobre a necessidade de aprofundar os estudos acerca da teoria. Pudemos notar, por exemplo, analisando os depoimentos das professoras, o reconhecimento da necessidade de ofertarmos diferentes situações-problema com graus distintos de complexidade, aumentando o desafio apresentado aos estudantes.

Tais evidências são observadas, por exemplo, no depoimento da Professora Emanuela: "Eu acho que é construção, por isso você tem sempre que ir desafiando, vai aumentando o desafio vai chegar uma hora que isso fica lógico para ele [referindo-se ao aluno]. Se não tem desafio pode ser que com o tempo fique até desestimulante."

Em síntese, embora haja evidências de desenvolvimento nos conhecimentos dos professores que estudaram essa teoria, o grupo compreendia já naquele momento que essa construção é contínua e precisaríamos aprofundar um pouco mais nossos estudos, atrelandoos às práticas das professoras na sala de aula, a fim de estimular reflexões sobre a prática e mudanças na concepção do ensino com situações-problema envolvendo as estruturas aditivas. 


\section{Ampliando os conhecimentos sobre a Teoria do Campo Conceitual Aditivo}

$\mathrm{Na} 14^{\mathrm{a}}$ sessão retomamos um instrumento elaborado pela Secretaria Estadual da Educação de São Paulo (SEE) e solicitamos ao grupo a análise cada categoria apresentada e a elaboração de outras situações que pudessem ser propostas aos alunos de forma que uma mesma categoria fosse apresentada com diferentes desafios, considerando a classificação dada por Vergnaud (2009).

\begin{tabular}{|l|l|}
\hline $\begin{array}{l}\text { Situações presentes no Documento da } \\
\text { SEE }\end{array}$ & $\begin{array}{l}\text { Reelaboração das professoras } \\
\text { participantes }\end{array}$ \\
\hline $\begin{array}{l}\text { 1-Tenho 3 bolinhas azuis e 4 bolinhas } \\
\text { vermelhas. Quantas bolinhas eu tenho? }\end{array}$ & $\begin{array}{l}\text { 1-Tenho 14 bolinhas coloridas. Sendo que 9 são } \\
\text { verdes e o restante são azuis. Quantas são as } \\
\text { bolinhas azuis? }\end{array}$ \\
\hline $\begin{array}{l}\text { 2-Tinha 7 bolinhas de gude e dei 3 para meu } \\
\text { amigo. Com quantas bolinhas fiquei? }\end{array}$ & $\begin{array}{l}\text { 2-Tinha 7 bolinhas de gude e ganhei 6 de meu } \\
\text { amigo. Com quantas bolinhas fiquei? }\end{array}$ \\
\hline $\begin{array}{l}\text { 3-Lia tem 315 figurinhas e Jorge tem 184 } \\
\text { figurinhas. Quem tem mais figurinhas? } \\
\text { Quantas a mais? }\end{array}$ & $\begin{array}{l}\text { 3-Lia tem 231 figurinhas e Jorge tem 23 a } \\
\text { mais. Quantas figurinhas têm Jorge? }\end{array}$ \\
\hline
\end{tabular}

Quadro 8: Comparação situações reelaboradas pelas professoras e-presentes no documento da SEE.

Observando as informações contidas no quadro, o grupo identificou na situação 1 a ideia de composição. Pudemos notar ainda que a situação reelaborada pelo grupo apresentava grau de dificuldade diferente do sugerido pela SEE. A opção foi modificar o tipo de situação e não a ordem das quantidades envolvidas. Observamos que, enquanto a situação proposta no documento solicitava o todo (protótipo), a elaborada pelas professoras solicitava a parte.

Discutimos no grupo o fato de que a situação 2, no documento da SEE, envolvia a ideia de transformação negativa, os elaborados pelas docentes utilizavam-se da ideia de transformação positiva, porém, com o mesmo grau de dificuldade.

Na situação 3 apresentada pelo documento da SEE são apresentados o referente e o referido e questiona-se sobre a relação que existe entre eles, ou seja, deve-se considerar o valor do referido (315) e o valor do referente (184) e "responder: Quem tem mais figurinhas?" é preciso também responder "Quantas figurinhas o referido tem a mais do que o referente."

Embora seja usada na situação a palavra "a mais" para responder "Quantas a mais?" pode-se usar como estratégia de resolução uma subtração para calcular a diferença. Observamos que na situação 3 reelaborada pelas professoras encontramos também o uso da palavra "a mais" no entanto, podemos considerar que "pode funcionar até" como uma "dica" uma vez que a palavra é congruente com a operação que resolve. Notamos, assim que a situação apresentada pela SEE é mais complexa, para resolvê-la é preciso que a criança compreenda a 
ideia da situação, fazer a relação entre a quantidade de figurinhas do referido e do referente e responder “quantas a mais?”. A situação reelaborada pelas professoras é menos complexa, pois ao adicionar as duas quantidades apresentada na situação é possível responder "Quantas figurinhas tem Jorge?” Nossas análises, a partir das situações elaboradas pelas professoras, nos levaram a perceber que havia indícios de que, em termos gerais, os estudos desenvolvidos com o grupo contribuíram para a ressignificação de conhecimentos das professoras. Acreditamos que tal fato poderá favorecer a organização e as escolhas de situações que perpassam pelas diferentes categorias, podendo, assim, dar condições para as professoras melhor planejarem tarefas e propostas de intervenção, de forma a favorecer a compreensão de seus alunos.

Acreditamos que os estudos realizados na escola podem ter favorecido uma atuação mais consciente das professoras na medida em que consideraram aspectos das classificações e categorias propostas por Vergnaud (2009) que, segundo pesquisas, alteram o grau de dificuldade da situação. Todavia, nos deparamos ainda naquele momento com muitas dúvidas em relação à complexidade observada nas diferentes categorias. Percebemos que precisaríamos de mais tempo para superar algumas das dificuldades de compreensão, especialmente, as relativas aos esquemas dos alunos quando se deparam com situações que exigem o pensamento de reversibilidade. O excerto a seguir justifica essa nossa observação:

É isso que é importante trabalhar com a mesma situação [classificação] de problema, mas de

forma diferente, podendo inverter. (PROFESSORA EVA)

Quando invertemos a pergunta, muda o jeito de ele pensar? (PESQUISADORA)

Muda. A ideia é diferente. (PROFESSORA EVA)

É, a ideia é diferente e a maneira como ele vai resolver também. (PROFESSORAFARA)

Como ele vai chegar na resolução. (PROFESORA EVA)

E exige pensamento diferente para resolver? (PESQUISADORA)

Exige. (DILZA)

Lembra que já havíamos estudado que a proposta do Vergnaud [referindo-se ao texto estudado] é de que o professor deve apresentar diferentes categorias. Então assim podemos

diversificar, apresentando diferentes desafios para os alunos.(PESQUISADORA)

Vocês já tinham pensado em reconstruir as situações propondo essa diversificação dentro de

uma mesma categoria? (PEQUISADORA)

Não, agora que eu fiz essa atividade que eu pude pensar. (PROFESSORAFARA)

Ontem, por exemplo, eu trabalhei com situações-problema agora eu posso trabalhar com

aquele mesmo problema só que em outra situação [categoria]. A criança vai pensar diferente para

resolver. (PROFESSORA FARA)

A criança também pode questionar, porque ela vai perceber que precisa de outro jeito para

resolver. (PROFESSORA EVA)

$\mathrm{Eu}$ achei interessante, porque eu descobri mais uma forma de trabalhar com eles.

(PROFESSORA FARA)

- Eu também compreendi agora como fazer. (PROFESSORAEVA)

Por que vocês acham que nunca tinham pensado nessa possibilidade? (PESQUISADORA)

Porque eu nunca tinha estudado Matemática antes. A teoria me ajudou a pensar nessas

possibilidades. (PROFESSORA FARA)

- É o ensino tradicional que não leva o professor a pensar nessa construção. A gente só trabalhava com os problemas prototípicos (PROFESSORA EVA)

Quadro 9: Diálogo que retrata o momento de reflexão sobre a prática durante a $14^{\mathrm{a}}$ sessão de estudos 
Consideramos, assim como Vergnaud (2011), que o professor tem papel importante para apoiar e incentivar o aluno a refletir e levantar hipóteses para que seja possível construir novos esquemas.

Analisando o ocorrido e considerando as experiências que tivemos no decorrer de nossos estudos, as discussões com o grupo e a articulação com os aspectos teóricos tornaram significativa a construção do conhecimento sobre a Teoria dos Campos Conceituais, pois provocaram reflexões sobre a prática e a mudança de concepções, favorecendo ao grupo de professores uma melhor compreensão do próprio currículo. O diálogo das professoras no grupo de estudos pôde exemplificar melhor essas nossas considerações.

Esse diálogo atesta ser necessário que processos de formação continuada desenvolvidos por meio de grupos de estudo ou não, ofereçam oportunidades aos professores de estudar e analisar resultados de investigações da área da Educação Matemática. Constatamos, nesses depoimentos, informações que evidenciam que a reflexão sobre a prática ocorreu na medida em que os professores participantes estudavam e sentiam-se mais seguros de suas potencialidades e limitações. Observamos também que esse processo permitiu a ampliação de algumas reflexões sobre a relação entre o ensino e a aprendizagem, especialmente, acerca da classificação proposta por Vergnaud (2009).

\section{Considerações Finais}

A análise dos dados aqui apresentados nos permite fazer a defesa de que é possível (re)significar conhecimentos de professores em grupos que estudam na própria escola. $\mathrm{O}$ conhecimento permite ao grupo uma maior cumplicidade e, dessa forma, é importante ir além da simples troca de experiências. É necessário apresentar teorias e resultados de pesquisas que favoreçam a reflexão sobre a prática docente.

Consideramos ser de fundamental importância que o professor reflita sobre a própria prática. No entanto, é preciso avançar. É preciso que favoreçam espaços de estudo que possibilitem a vivência de mudanças da prática, também à luz de resultados de pesquisa e teoria, como ocorreu aqui.

Finalmente, acreditamos que nosso estudo mostrou que a (re)significar de conhecimentos neste grupo foi potencializada pela retomada dos conhecimentos matemáticos, mas não quaisquer conhecimentos - fomos além do conhecimento comum do conteúdo para o especializado. Avançamos para o que Ball et al (2008) consideram, conhecimento do conteúdo e do ensino; conhecimento do conteúdo e do estudante e conhecimento curricular. Neste estudo observamos ainda haver uma relação forte entre a (re)significação dos conhecimentos e a segurança demonstrada pelos participantes: tanto a autoconfiança como a confiança mútua. 
Referências

BALL, D. L.; THAMES, M. H.; PHELPS, G. CONTENT KNOWLEDGE FOR TEACHING: WHAT MAKES IT SPECIAL? IN: JOURNAL OF TEACHER EDUCATION, NOVEMBER/DECEMBER, VOL. 59,P. 389-407, 2008.

ETCHEVERRIA, T.C. Educação continuada em grupos de estudos: possibilidades com foco no ensino da geometria / Teresa Cristina Etcheverria. Porto Alegre, 2008.

MAGINA, S.; CAMPOS, T. M. M.; GATIRANA, V.; NUNES, T. Repensando adição

e subtração. Contribuições da teoria dos campos conceituais. $3^{\text {a }}$ ed. - São Paulo: PROEM, 2008.

MIRANDA, M. S. Uma investigação sobre a (re)construção do conhecimento de professores participantes de um grupo que estuda o campo conceitual aditivo. São Paulo: UNIAN, 2014, 206 f, Dissertação (Mestrado em Educação Matemática) - Programa de Pós-Graduação em Educação em Educação Matemática,Universidade Anhanguera, São Paulo, 2014.

MORAES, R.; GOMES, V. Dissoluções e cristalizações: teorização dentro de grupos reflexivos de professores em escolas. In: MORAES, Roque;

NÓVOA, A. Formação de professores e profissão docente. In NÓVOA, Antônio (Coord.) Os professores e a sua Formação. Lisboa, Portugal: Publicações Dom Quixote, 1997. p.15-33.

PEREIRA, M. D. Um estudo sobre interpretações das diretrizes curriculares para o curso de licenciatura em matemática por uma instituição federal de São Paulo. São Paulo: UNIBAN, 2013, p.271. Tese (Doutorado em Educação Matemática) - Programa de Pós-Graduação em Educação em Educação Matemática, Universidade Bandeirante de São Paulo, São Paulo, 2013. SANTANA, E. R. S. Estruturas aditivas: o suporte didático influencia a aprendizagem do estudante? Tese (Doutorado em Educação) - Pontifícia Universidade Católica de São Paulo, São Paulo, 2010.

SERRAZINA, L. Desenvolvimento profissional de professores. Contributos para reflexão, 1999.

SHULMAN, Lee. Those Who Understand Knowledge Growth in Teaching. Educational Researcher, American Educational Research Association, 1986.

VERGNAUD. G. La théorie des champs conceptuels. Recherches en Didactique des Mathématiques, 10 (23), p. 133-170, 1990.

. Lev Vygotski: pedagogo e pensador do nosso tempo. Porto Alegre: GEEPA, 2004.

ISSN 2526-2882

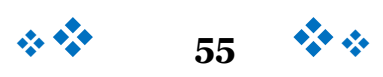


A criança a matemática e a realidade : problemas do ensino de matemática na escola elementar / Gerard Vergnaud. Tradução Maria Lúcia Faria Moro. Revisão técnica Maria Tereza Carneiro Soares, Curitiba : UFPR, 2009.

- Teoria dos campos conceituais. In: Campos, T.M.M. (Coord.). Curso monográfico de altos estudos. São Paulo: Uniban, 2010.

G. O longo e o curto prazo na aprendizagem da matemática. Educar em Revista, Curitiba, Brasil, n. Especial 1/2011, p. 15-27, Editora UFPR. 2011

\section{Agradecimentos}

Agradecemos o apoio financeiro recebido da Coordenação de Aperfeiçoamento de Pessoal de Nível Superior - CAPES - Brasil, por meio do Projeto Observatório da Educação (Convênio ou AUXPE n. ${ }^{\circ}$ : OE 99/10), bem como a disponibilidade das escolas parceiras deste projeto.

\section{Biografia Resumida}

Angélica da Fontoura Garcia Silva. Doutora em Educação Matemática pela Pontifícia Universidade Católica de São Paulo (PUC-SP). Professora da Universidade Anhanguera de São Paulo (UNIAN- SP) Integrante do Grupo de Pesquisa "Formação de Professores que ensinam Matemática”.

Currículo Lattes: http://lattes.cnpq.br/5279665144777466

Contato: angelicafontoura@gmail.com

Mirtes Souza Miranda, Mestre em Educação Matemática pela Universidade Anhanguera de São Paulo (UNIAN- SP). Professora da Secretaria Estadual da Educação de São Paulo. Integrante do Grupo de Pesquisa "Formação de Professores que ensinam Matemática”.

Currículo Lattes: http://lattes.cnpq.br/8338135452779122 Contato: mirtes2015miranda@gmail.com

Ruy Cesar Pietropaolo. Doutor em Educação Matemática pela Pontifícia Universidade Católica de São Paulo ( PUC-SP). Professor da Universidade Anhanguera de São Paulo (UNIANSP) Integrante do Grupo de Pesquisa "Formação de Professores que ensinam Matemática”.

Currículo Lattes: http://lattes.cnpq.br/8731431789517806

Contato: rpietropaolo@gmail.com 